\title{
Canine non-B, non-T NK lymphocytes have a potential antibody-dependent cellular cytotoxicity function against antibody- coated tumor cells
}

Yoseop Kim ${ }^{1,2+}$, Soo-Hyeon Lee ${ }^{3,4+}$, Cheol-Jung Kim ${ }^{1}$, Je-Jung Lee ${ }^{5}$, Dohyeon Yu ${ }^{6}$, Soomin Ahn ${ }^{6}$, Dong-Jun Shin ${ }^{7^{*}}$ and Sang-Ki Kim ${ }^{1,3,7^{*}}$ (D)

\begin{abstract}
Background: The antibody-dependent cellular cytotoxicity (ADCC) is a cell-mediated immune defense mechanism in which effector immune cells actively lyse antibody-coated target cells. The ADCC of tumor cells is employed in the treatment of various cancers overexpressing unique antigens, and only natural killer (NK) cells are known to be major effectors of antibody mediated ADCC activity. Canine NK cells are still defined as non-B, non-T large granular lymphocytes because of the lack of information regarding the NK cell-restricted specific marker in dogs, and it has never been demonstrated that canine NK cells have ADCC ability against tumor cells. In the present study, we investigated whether canine non-B, non-T NK cells have ADCC ability against target antibody-coated tumor cells, using cetuximab and trastuzumab, the only human antibodies reported binding to canine cancer cells.

Results: Activated canine non-B, non-T NK cells $\left(C D 3^{-} C D 21^{-} C D 5^{-}{ }^{-} C R a \beta^{-} T C R y \delta^{-}\right)$for $13 \sim 17$ days ex vivo showed ADCC ability against trastuzumab- or cetuximab-coated target tumor cells expressing various levels of human epidermal growth factor receptor 2 (HER-2) and epidermal growth factor receptor (EGFR). Trastuzumab and cetuximab induced significant ADCC responses of canine NK cells even in CMT-U334 and CF41.Mg cells expressing low levels of HER-2 and/or EGFR, as well as in SKBR3 and DU145 cells overexpressing HER-2 and/or EGFR. The trastuzumab-mediated ADCC activity of NK cells was significantly enhanced by treatment with rclL-21.

Conclusions: The results of this study suggest that canine non-B, non-T NK lymphocytes have a potential ADCC function and that combinational strategies of monoclonal antibodies with either cytokines, which activate NK cells in vivo, or adoptive transfer of NK cells may be a feasible method for amplifying the efficacy of immunotherapy against malignant cancers even with very low expression of target molecules in dogs.
\end{abstract}

Keywords: Natural killer cells, Canine, Antibody-dependent cellular cytotoxicity, Trastuzumab, Cetuximab

\footnotetext{
* Correspondence: shin-phd@daum.net; sangki@kongju.ac.kr

Yoseop Kim and Soo-Hyeon Lee share first authorship

${ }^{7}$ Research Institute for Natural Products, Kongju National University,

Yesan-gun, Chungnam 32439, Republic of Korea

${ }^{1}$ Department of Companion and Laboratory Animal Science, College of

Industrial Science, Kongju National University, Yesan-gun, Chungnam 32439,

Republic of Korea

Full list of author information is available at the end of the article
}

C The Author(s). 2019 Open Access This article is distributed under the terms of the Creative Commons Attribution 4.0 International License (http://creativecommons.org/licenses/by/4.0/), which permits unrestricted use, distribution, and reproduction in any medium, provided you give appropriate credit to the original author(s) and the source, provide a link to the Creative Commons license, and indicate if changes were made. The Creative Commons Public Domain Dedication waiver (http://creativecommons.org/publicdomain/zero/1.0/) applies to the data made available in this article, unless otherwise stated. 


\section{Background}

The range of cancers observed in dogs is known to be as diverse as that observed in humans, and cancers in dogs and humans share many features, including histological and genetic molecular alterations, and biological behavior. Many conventional therapies applied to canine patients are nearly identical to those used to treat human patients [1]. Advances in conventional therapies, such as surgery, chemotherapy, and radiotherapy have contributed to the achievement of local control of the primary tumor, however, in general have failed to improve survival for cancer patients. Immunotherapy has emerged as an important addition to conventional cancer therapies [2]. In particular, natural killer (NK) cell-based immunotherapy and passive immunotherapy with targeted monoclonal antibodies have been the most successful therapeutic strategies for cancers in human [3-5].

NK cells are key components of the innate immune system, and mediate innate defenses against cancers and viral infections. NK cells are a powerful tool in cancer immunotherapy due to their robust effector functions. One of the potent effector mechanisms of NK cells is antibody-dependent cellular cytotoxicity (ADCC) mediated by antibody-coated target cells $[4,5]$. The ADCC activity of NK cells is thought to play a crucial role in antitumor effects of therapeutic monoclonal antibodies for cancer [6, 7]. Only NK cells are known to be major effectors of antibody-mediated ADCC activity [6, 8]. The antitumor efficacy of target monoclonal antibody therapies has been shown to be NK cell-dependent [4, 5]. Clinical studies of NK cell-based immunotherapy combined with target monoclonal antibody therapies have shown significantly improved disease outcome in human cancer patients $[9,10]$. However, the development of this approach in dogs has been precluded due to lack of information on canine NK cells and the lack of comparable therapeutic antibodies [11-13]. Canine NK cells can be defined as non-B, non-T large granular lymphocytes because of the lack of information regarding specific NK cell markers. Furthermore, it has never been demonstrated that canine NK cells have ADCC ability against antibody-coated tumor cells.

Therapeutically efficacious canine monoclonal antibodies are still not available, although several canine specific monoclonal antibodies are recently in various stages of development for canine cancers [14-17]. A recent study revealed significant homology between human and canine epidermal growth factor receptor (EGFR) and human epidermal growth factor receptor 2 (HER-2) and indicated that both molecules contain highly conserved epitopes for the therapeutic antibodies cetuximab and trastuzumab, with targeting inducing the tumoristatic effects of canine tumor cells overexpressing EGFR or HER-2 [18]. In the present study, we investigated whether the ADCC of canine NK cells was induced by antibody-coated cancer cells using cetuximab and trastuzumab, the only human antibodies reported to bind to canine cancer cells. The results of this study demonstrate that activated canine non- $\mathrm{B}$, non- $\mathrm{T}$ NK lymphocytes have a potential ADCC function against antibody-coated tumor cells even with very low expression of target antigens.

\section{Results \\ Expression of HER-2 and EGFR on the surface of target tumor cells}

To select the appropriate cells for the analysis of ADCC function in canine NK cells and confirm the antitumor effects of trastuzumab and cetuximab on canine tumor cells, the surface expression of HER-2 and/or EGFR was first investigated in canine tumor cell lines by flow cytometry. Four canine urinary bladder cancer cell lines, four mammary gland cancer cell lines, and canine thyroid adenocarcinoma (CTAC) cells were screened for their EGFR and HER-2 expression levels (Additional file 1: Methods). Based on the results of flow cytometry analysis, the CMT-334 and CF41.Mg cell lines were selected as the mammary gland tumor cells with the highest expression of HER-2 and/or EGFR among the nine cell lines tested for this study (Fig. 1 and Additional file 1: and Figure S1). SKBR3 and DU145 cells, which have been reported to highly express HER-2 and/or EGFR $[19,20]$, were used as positive controls. As shown in Fig. 1, the SKBR3 cells expressed high levels of HER2 (relative mean fluorescence intensity, rMFI, $259.0 \pm$ 120.4) and moderate levels of EGFR (rMFI $=18.4 \pm$ 6.5). The DU145 cells expressed low levels of HER-2 $(4.8 \pm 0.4)$ and moderate levels of EGFR $(17.8 \pm 6.5)$. The CMT-U334 cells expressed low levels of HER-2 $(6.3 \pm 1.2)$ and low levels of EGFR $(2.9 \pm 0.5)$. CF41.Mg cells expressed low levels of HER-2 $(3.7 \pm 0.5)$ and did not express EGFR $(0.9 \pm 0.1)$ on their surface.

\section{Effects of trastuzumab and cetuximab on the viability, proliferation, and apoptosis of target tumor cells}

To assess the direct anti-cancer effects of trastuzumab and cetuximab on canine tumor cells expressing low levels of EGFR and/or HER-2, the cell viability of CMTU334 and CF41.Mg cells was analyzed after treatment with trastuzumab $(10 \mu \mathrm{g} / \mathrm{ml})$ or cetuximab $(10 \mu \mathrm{g} / \mathrm{ml})$. SKBR3 and DU145 cells, which have been reported to be sensitive to trastuzumab and/or cetuximab, were used as controls. The cell viability was not changed in CMTU334 and CF41.Mg cells for $96 \mathrm{~h}$ after treatment with trastuzumab or cetuximab, whereas the cell viability of SKBR3 was significantly reduced in a time-dependent manner for $96 \mathrm{~h}$ after trastuzumab treatment compared with cells treated with human IgG isotype control 


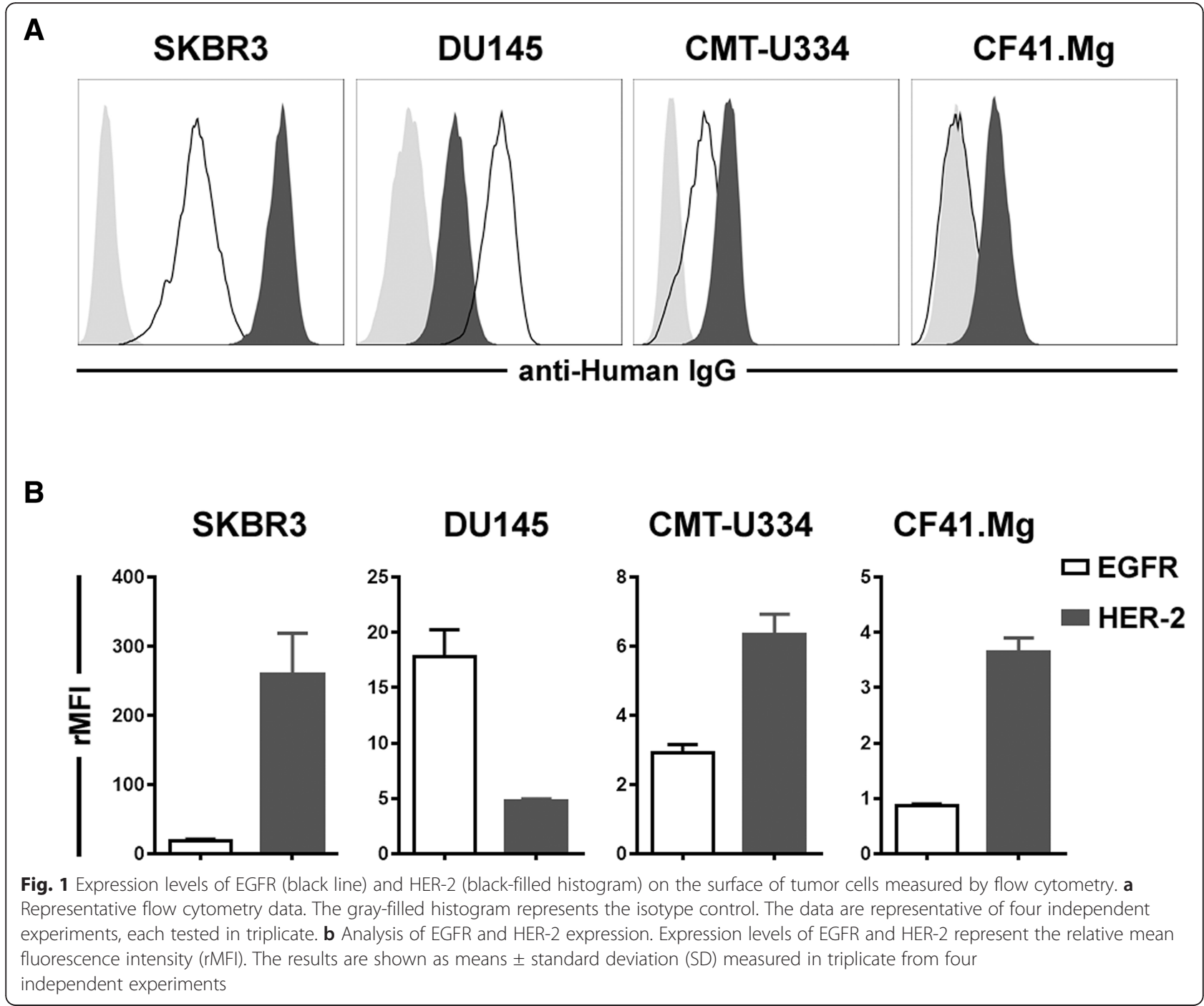

antibody $(99.5 \pm 8.0 \%)$ or medium only $(100.0 \pm 0.0 \%)$ $(p<0.05)$. After $96 \mathrm{~h}$ of incubation with trastuzumab, the viability of SKBR3 cells was reduced to $53.4 \pm 4.4 \%$. Cetuximab did not inhibit the viability of SKBR3 cells until $72 \mathrm{~h}$ after treatment. However, the viability of SKBR3 cells was significantly decreased $(91.1 \pm 5.2 \%)$ after $96 \mathrm{~h}$ of cetuximab treatment compared with that of the IgG isotype control group $(99.5 \pm 8.0 \%)$ and mediaonly group $(100.0 \pm 0.0 \%) \quad(p<0.05)$. The viability of DU145 cells after treatment with cetuximab $(90.1 \pm$ $7.0 \%)$ was slightly reduced compared with that of the cells treated with human IgG isotype control antibody $(101.3 \pm 5.5)$ or media only $(100.0 \pm 0.0)(p<0.05)$; however, no changes were observed in the viability of the cells after trastuzumab treatment (Fig. 2).

To further investigate the growth-inhibitory effects of cetuximab and trastuzumab on canine cancer cells, the effects of both monoclonal antibodies on the proliferation and apoptosis of the target tumor cells were also examined. The expression of intracellular Ki-67 was analyzed to evaluate the cell proliferation by flow cytometry. Figure 3 shows the effects of cetuximab and trastuzumab on target cell proliferation. Neither antibody affected the proliferation of CMT-U334 and CF.41 Mg cells after $96 \mathrm{~h}$ of treatment. Although the difference was not statistically significant, trastuzumab tended to decrease the proliferation of SKBR3 $(54.9 \pm 15.0 \%)$ compared with that of the IgG isotype control group (68.4 \pm $12.9 \%)$ and media-only group $(66.3 \pm 13.7 \%)$, and cetuximab tended to decrease the proliferation of DU145 $(76.8 \pm 14.3 \%)$ compared with that of the IgG isotype control group $(92.1 \pm 3.8 \%)$ and media-only group $(90.6 \pm 7.2 \%)$ after $96 \mathrm{~h}$ of treatment. The percentage of cells undergoing death was determined by the expression of propidium iodide (PI) and annexin V in all cells. Figure 4 shows the effects of cetuximab and trastuzumab 


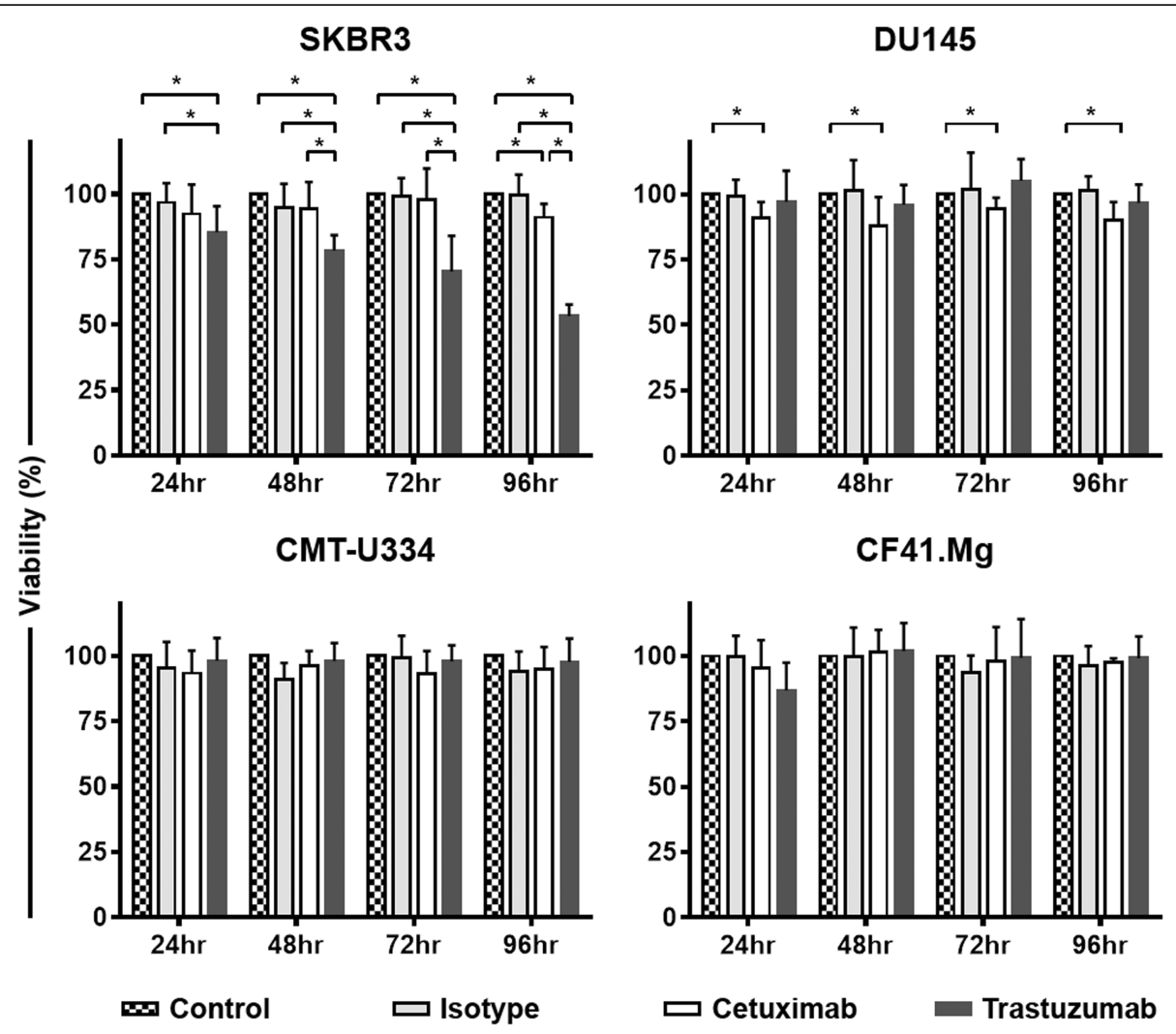

Fig. 2 Effect of trastuzumab and cetuximab on the cell viability of tumor cells. The susceptibility of canine mammary gland tumor cells expressing EGFR and/or HER-2 to cetuximab and trastuzumab was investigated in a tetrazolium-based cell viability assay. SKBR3 and DU145 cells that had been reported to overexpress HER-2 and EGFR were used as positive controls. The viability of the tumor cells after treatment with trastuzumab, cetuximab, or human IgG isotype antibody was evaluated every $24 \mathrm{~h}$ for $96 \mathrm{~h}$. Tumor cells incubated in media alone served as a control. The values represent the means \pm standard deviation (SD) of five independent experiments, each tested in triplicate. ${ }^{*} p<0.05$

on target cell apoptosis. After $96 \mathrm{~h}$ of treatment, trastuzumab enhanced apoptosis significantly in SKBR3 cells $(33.2 \pm 11.3 \%)$ compared with that in the cetuximab group $(24.2 \pm 8.2 \%)$, the isotype IgG antibody group $(21.0 \pm 8.4 \%)$, and the media-only group $(21.0 \pm 7.1 \%)$ $(p<0.05)$. Trastuzumab increased apoptosis slightly in CMT-U334 cells $(26.2 \pm 9.5 \%)$ compared with that in the isotype IgG antibody group $(20.9 \pm 7.9 \%)$ and media-only group $(22.2 \pm 8.2 \%)(p<0.05)$. In CF41.Mg cells, there was no significant difference compared with the isotype IgG antibody $(34.0 \pm 8.3 \%)$, but trastuzumab significantly increased apoptosis $(38.4 \pm 6.8 \%)$ compared with the cetuximab group $(33.9 \pm 7.1 \%)$ and media-only group $(32.5 \pm 8.4 \%) \quad(p<0.05)$. Cetuximab significantly increased apoptosis only in DU145 cells $(9.1 \pm 3.2 \%)$ compared to the isotype IgG antibody group $(6.4 \pm 1.4 \%)$ and media-only group $(6.2 \pm 2.1 \%)(p<0.05)$.

ADCC activity of canine non-B, non-T NK cells in response to trastuzumab- or cetuximab-coated tumor cells Canine non-B, non-T NK cells were selectively expanded for 13 17 days ex vivo until the purity of the cells reached greater than $90 \%$ depending on the donor. The phenotype of most of these expanded cells was $\mathrm{CD} 3^{-} \mathrm{CD} 21^{-} \mathrm{CD} 5^{-} \mathrm{TCR} \alpha \beta^{-} \mathrm{TCR} \gamma \delta^{-}$, and the purity of the cells was $93.4 \pm 2.7 \%$ (Fig. $5 \mathrm{a}$ ). The mRNA expression levels of NK-related molecules, including CD16, in the expanded cells were the same as those in our previous reports (data not shown) [13, 21, 22]. To assess the ADCC ability of canine non- $\mathrm{B}$, non- $\mathrm{T}$ NK cells against the antibody-coated target tumor cells, the 4-h cytotoxicity of NK cells was investigated after coculture with trastuzumab- or cetuximab-coated CMTU334, CF41.Mg, SKBR3, and DU145 cells at a 4:1 E:T ratio. As shown in Fig. 5b, trastuzumab significantly enhanced the cytotoxic activities of canine NK cells against not only SKBR3 expressing high levels of HER-2 but also DU145 and CMT-U334 expressing low levels of HER-2 $(p<0.01)$. Canine NK cells also showed significantly higher cytotoxicity in trastuzumab-coated CF41.Mg cells expressing very low levels of HER-2 than in control cells not coated with antibodies $(p<0.01)$. The isotype IgG control antibody did not influence the cytotoxicity of NK cells against all four target tumor cells compared with 


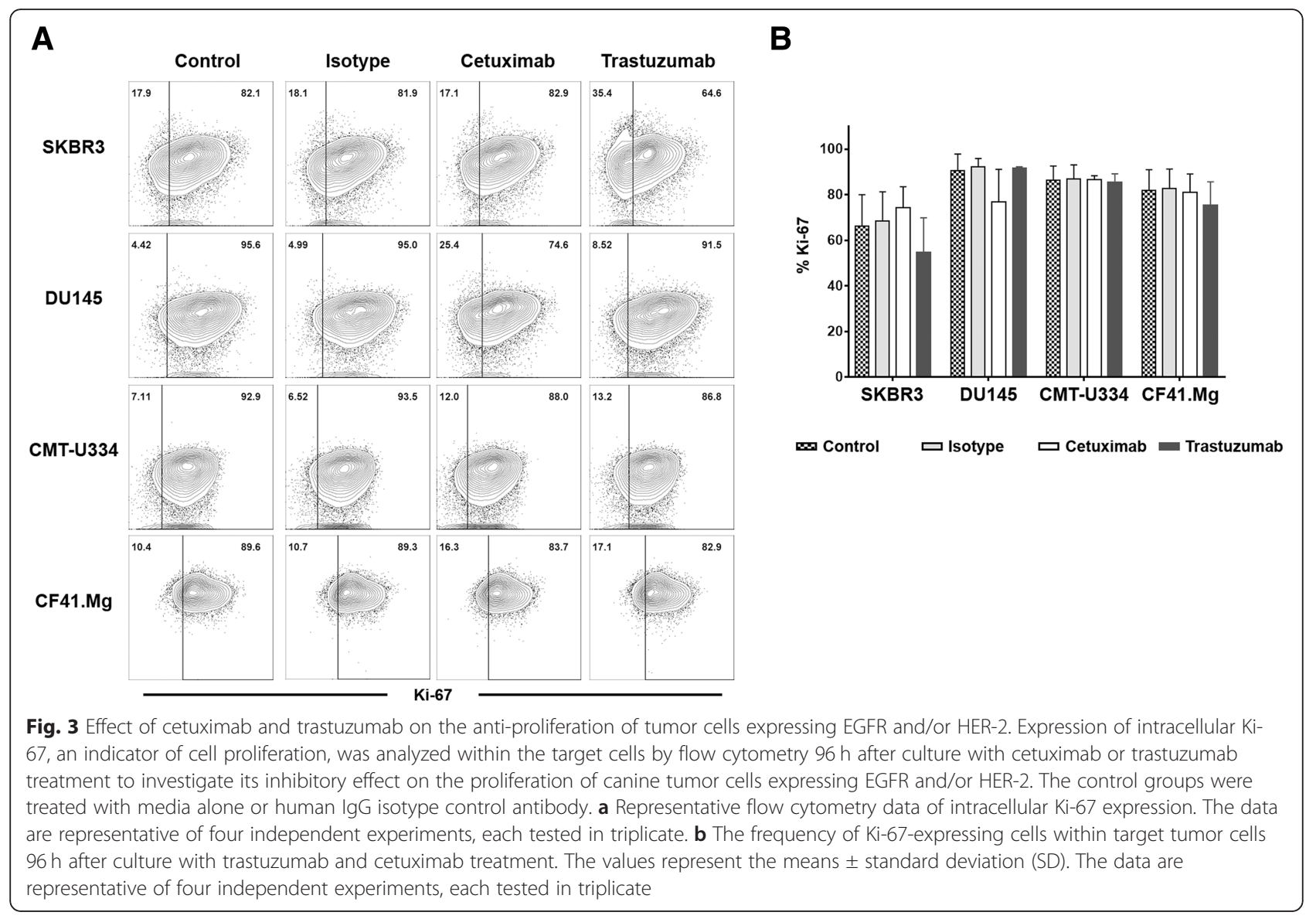

control cells not treated with antibody. With the exception of CF41.Mg cells that do not express EGFR, cetuximab also significantly increased the cytotoxicity of NK cells in DU145, SKBR3, and CMT-U334 cells expressing various levels of EGFR $(p<0.01)$.

\section{Augmentation of ADCC activity and interferon (IFN)- $\gamma$ production in NK cells in response to trastuzumab-coated SKBR3 cells by IL-21}

To determine the effects of additional IL-21 stimulation on the effector functions of NK cells against trastuzumab-coated tumor cells, the cultured NK cells were further treated with IL-21 for 2 days before harvesting on day 14. SKBR3 cells expressing high levels of HER-2 were treated with trastuzumab, isotype IgG antibody, and media only and then were co-cultured with NK cells that had been treated with or without IL-21. As shown in Fig. 6a, 4-h cytotoxicity analysis revealed that the trastuzumab-mediated ADCC activity of NK cells against SKBR3 cells was enhanced significantly by cultured NK cells pretreated with IL-21 (66.1 $\pm 6.9 \%)$ compared with those without additional IL-21 stimulation $(57.1 \pm 5.2 \%)(p<0.05)$. Compared with control cells not treated with antibody, the isotype IgG control antibody did not affect the cytotoxicity of NK cells regardless of IL-21 stimulation against SKBR3 cells. We next assessed the IFN- $\gamma$ production of cultured NK cells stimulated with or without additional IL-21 in response to trastuzumab- or isotype IgG antibody-coated and uncoated SKBR3 cells after a 24h co-culture at a 10:1 E:T ratio. As shown in Fig. 6b, the production of IFN- $\gamma$ in NK cells was, with or without additional IL-21 stimulation, significantly increased in response to trastuzumab-coated SKBR3 cells compared with isotype IgG antibody-coated or antibody-untreated SKBR3 cells $(p<0.05)$. Additional stimulation of cultured NK cells with IL-21 further increased the production of IFN- $\gamma$ in response to trastuzumab-coated SKBR3 cells $(1832.7 \pm 92.9 \mathrm{pg} / \mathrm{ml})$ compared to NK cells untreated with IL-21 (2121.3 \pm $58.0 \mathrm{pg} / \mathrm{ml})(p<0.05)$.

\section{Discussion}

In this study, we investigated whether canine non-B, non-T NK cells possess ADCC function against antibody-coated tumor cells, using cetuximab and 

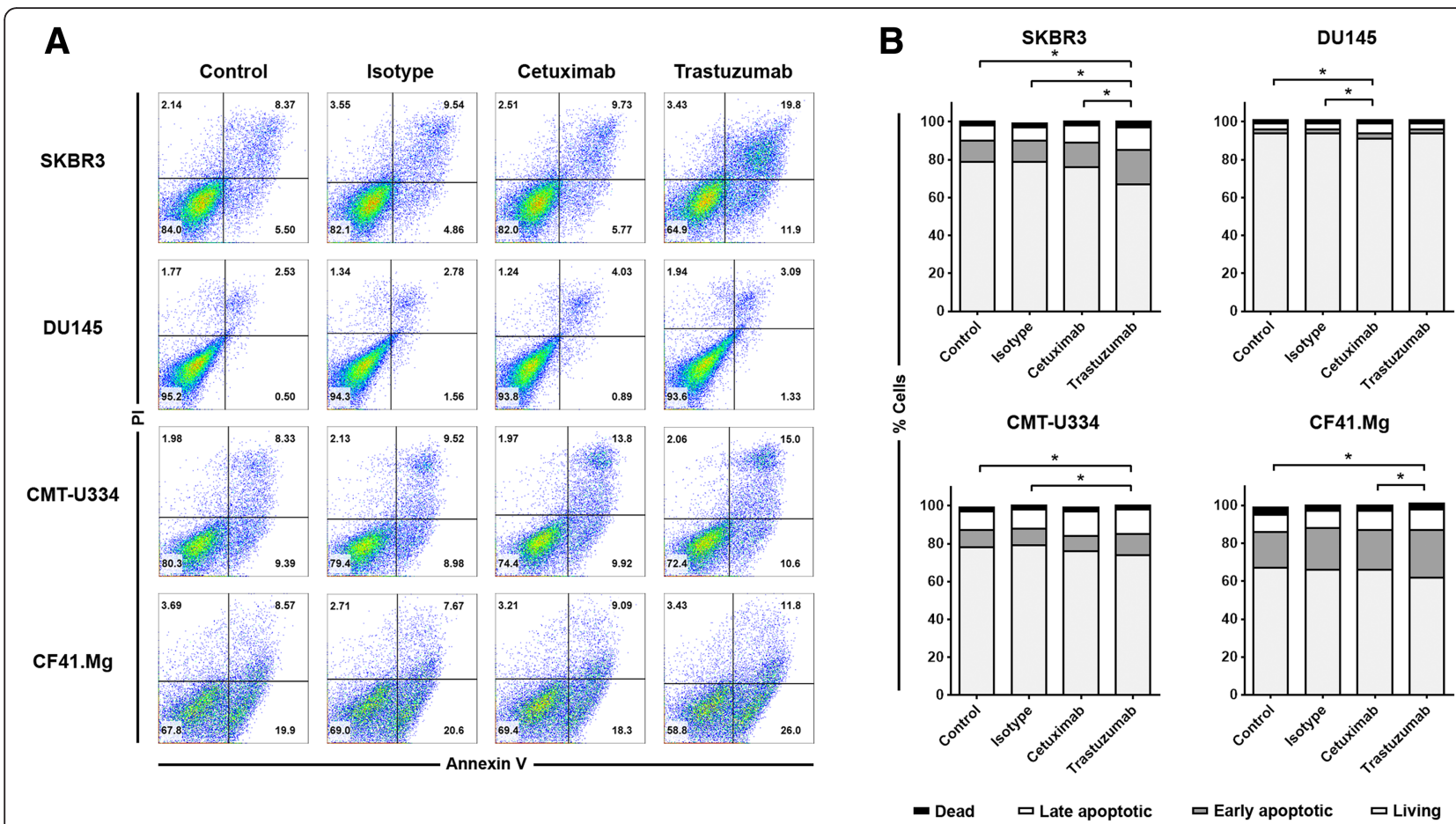

Fig. 4 Effect of cetuximab and trastuzumab on the cell death of tumor cells expressing EGFR and/or HER-2. Target tumor cells were stained with annexin V/propidium iodide (PI) to analyze apoptosis of cells after culture of the cells in complete medium containing $10 \mu \mathrm{g} / \mathrm{ml}$ of cetuximab or $10 \mu \mathrm{g} / \mathrm{ml}$ of trastuzumab for $96 \mathrm{~h}$. Control groups were treated with media alone or $10 \mu \mathrm{g} / \mathrm{ml}$ of human lgG isotype control antibody. a Representative flow cytometry data of annexin V/PI staining of cells from four independent experiments, each tested in triplicate. $\mathbf{b}$ The frequency of cell death $96 \mathrm{~h}$ after culture. The population of cells that was negative for both annexin $\mathrm{V}$ and PI was defined as living cells. Annexin $\mathrm{V}^{+} / \mathrm{PI}^{-}$cells were classified as early apoptotic cells, and double-positive cells were classified as late apoptotic cells. Annexin $\mathrm{V}^{-} / \mathrm{PI}^{+}$cells were classified as dead cells. The data are representative of four independent experiments, each tested in triplicate. ${ }^{*} p<0.05$

trastuzumab, the human antibodies reported to bind to canine cancer cells expressing EGFR and HER-2. EGFR (erbB1) and HER-2 (erbB2) are members of the ErbB receptor tyrosine kinase family that consists of four members, and the dimerization of the receptor that occurs after ligand binding to the extracellular domain finally controls various biological responses, such as the proliferation, survival, and migration of cells [23]. The overexpression of EGFR and HER-2 in different types of canine malignancies, such as mammary gland tumors [24, 25], osteosarcoma [26], gastric tumors [27], and brain tumors [28], has been reported. The molecular structures and biological functions of canine EGFR and HER-2 were found to be very similar to those of human EGFR and HER-2 [18]. Cetuximab, a chimeric IgG1 antibody against EGFR, and trastuzumab, a humanized IgG1 antibody against HER-2, are popular therapeutic antibodies that significantly improved the clinical outcome in EGFR- and HER-2-overexpressing human cancers, respectively [29]. A recent report demonstrated the direct tumoristatic effects of cetuximab and trastuzumab on canine mammary carcinoma cells expressing EGFR and HER-2 [18]. In the present study, we confirmed that cetuximab and trastuzumab antibodies were bound to canine EGFR and HER-2, respectively, on mammary gland carcinoma cells (Fig. 1). Although trastuzumab induced very marginal levels of apoptosis in both cell lines (Fig. 4), cetuximab and trastuzumab did not show effects on the cell growth and proliferation of CF41.Mg and CMT-U334 cells, both of which express low levels of HER-2 and EGFR (Figs. 2 and 3), These results are in agreement with human studies showing that the direct anti-cancer effects of cetuximab and trastuzumab were not observed in tumor cells expressing low levels of EGFR and HER-2, respectively [19, 30].

The anti-tumor efficacy of tumor targeting monoclonal antibodies are shown to be NK cell-dependent, because the NK cell-mediated ADCC activities of monoclonal antibodies are crucial for their anti-cancer effects [5-8]. Canine NK cells are still defined as non-B, non-T large granular lymphocytes because of the lack of information regarding the NK cell-restricted specific marker in dogs, although $\mathrm{CD}^{-} \mathrm{CD} 21^{-}$lymphocytes that express NKp46 (NCR1) are thought be a population of canine NK cells [31, 32]. In our previous studies, we selectively expanded canine non-B, non-T NK lymphocytes $\left(\mathrm{CD} 3^{-} \mathrm{CD} 21^{-} \mathrm{CD}^{-} \mathrm{CD} 4^{-} \mathrm{TCR} \alpha \beta^{-} \mathrm{TCR} \gamma \delta^{-}\right)$ex vivo from the PBMCs of healthy dogs, and characterized them 

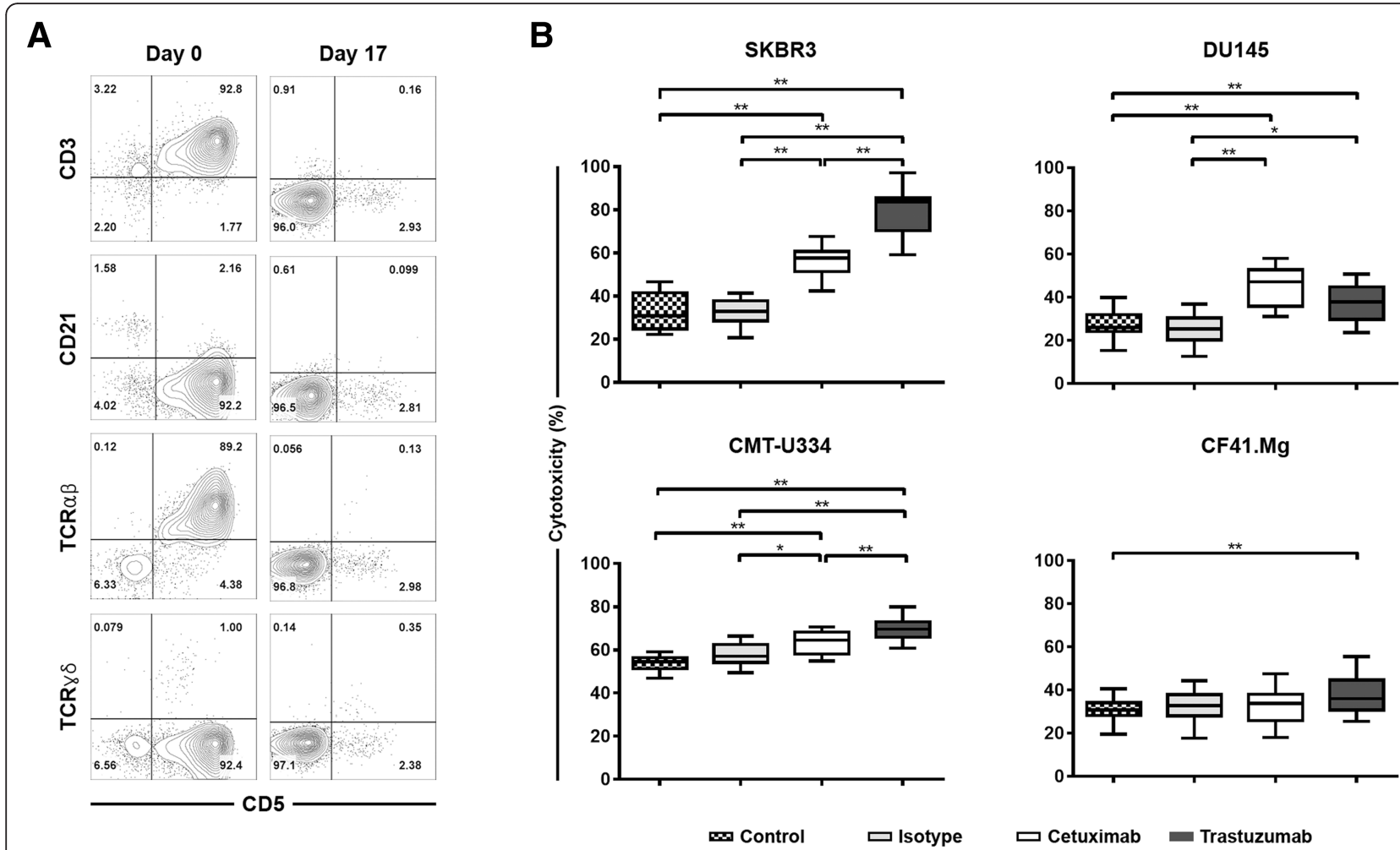

Fig. 5 Phenotype and antibody-dependent cellular cytotoxicity (ADCC) of cultured canine NK cells. a Phenotypic characteristics of expanded non-

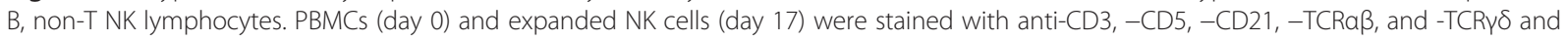
were analyzed via flow cytometry. Expanded NK cells (CD3- ${ }^{-}$D $\left.21^{-} C D 5^{-} T C R a \beta^{-} T C R y \delta^{-}\right)$exhibiting over $90 \%$ purity after culture were used to evaluate the ADCC effects of such cells in canine tumor cells. $\mathbf{b}$ The ADCC ability of expanded NK cells against target tumor cells pretreated with trastuzumab or cetuximab. The 4-h cytotoxicities of NK cells were measured at a 4:1 effector-to-target (E:T) ratio from triplicate reactions and 12 different donors. The cytotoxicity of NK cells against tumor cells pretreated with media alone or human isotype lgG antibody served as controls. The median, first (Q1) and third (Q3) quartiles, and the minimum and maximum are shown. ${ }^{*} p<0.05,{ }^{* *} p<0.01$

phenotypically and functionally [13]. These expanded NK lymphocytes expressed NK cell-related genes, including CD16 (FcyRIII) which is important for the ADCC function of NK cells [13, 21, 22, 33, 34]. In the present study, canine NK cells were expanded for 13 17 days under the same culture conditions used in our previous study (Fig. 5a) [13]. Most of canine non-B, non-T NK cells cultured in this condition expressed NKp46 on their surface (Additional file 1: Figure S2). We investigated the ADCC function of cultured non-B, non-T NK cells against the target tumor cells with various expression levels of HER-2 and/or EGFR. Trastuzumab and cetuximab induced significant ADCC responses of canine NK cells in tumor cells expressing HER-2 and/or EGFR, regardless of the degree of expression (Fig. 5b), suggesting that FcyRIII expressed on the surface of cultured canine NK cells can bind to the Fc constant regions of the human antibodies as reported by Bergeron et al. [35]. The canine NK cells showed significant ADCC capability against trastuzumab- and cetuximabcoated SKBR3 and DU145 overexpressing HER-2 and/or EGFR (Fig. 5b). Although both SKBR3 and DU145 are human-derived cancer cells, the results of significantly enhanced cytotoxic effects of NK cells against antibodycoated cells compared to controls may be sufficient to demonstrate ADCC function of canine NK cells. Notably, trastuzumab and cetuximab could efficiently stimulate the ADCC activity of canine NK cells even against tumor cells, which weakly express HER-2 and/or EGFR. Trastuzumab induced significant ADCC responses in CMT-U334 and CF41.Mg cells expressing low levels of HER-2. However, the magnitude of the difference in NK cell cytotoxicity against trastuzumab-uncoated and -coated CF41.Mg cells was too small to make biological significance. Cetuximab significantly stimulated ADCC activities in EGFR low-expressing CMT-U334 cells but not in CF41.Mg cells that do not express EGFR (Fig. 5b). These results are consistent with the findings in human studies showing that trastuzumab induces ADCC in HER-2-non-amplified breast cancer cells [7, 36]. On the other hand, trastuzumab and cetuximab did not stimulate ADCC activity of cultured NK cells against canine NK-sensitive CTAC (canine thyroid adenocarcinoma) cells that do not express HER-2 and EGFR (Additional file 


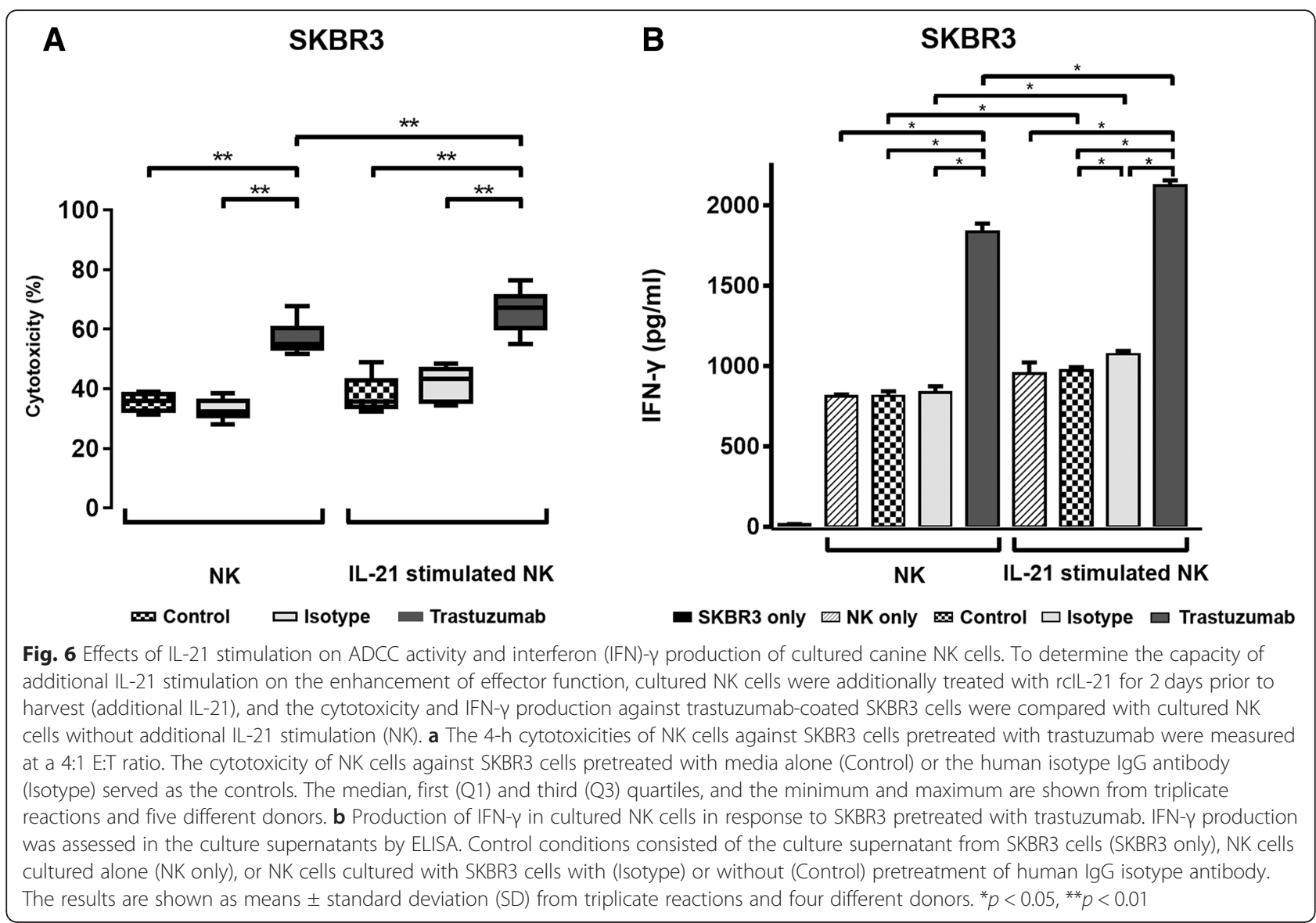

1: Figure S1 and S3). These results might indicate that a threshold level of HER-2 or EGFR expression is required for initiation of trastuzumab- or cetuximab-mediated ADCC enough to make a therapeutic difference [7].

Taken together, the results of this study demonstrate that activated canine non- $\mathrm{B}$, non- $\mathrm{T}$ NK lymphocytes have a potential ADCC function, and trastuzumab and cetuximab, which have a human IgG1 backbone, can induce strong ADCC activity of these cells against HER2- and EGFR-expressing tumor cells, respectively. Furthermore, canine NK lymphocytes are capable of ADCC function mediated by trastuzumab and cetuximab even in tumor cells with very low expression of HER-2 and EGFR. Recently, several canine specific anti-CD20 monoclonal antibodies and a chimeric version of antiEGFR antibody are in various stages of development for treatment of canine cancers [14-17]. Further clinical research should focus on the combinational strategies of these canine antibodies with therapies to enhance NK cell function for canine cancer patients.

\section{Conclusion}

The results of this study suggest that canine non- $B$, non$\mathrm{T}$ NK lymphocytes have a potential ADCC function and that combinational strategies of monoclonal antibodies with either adoptive transfer of NK cells or cytokines like interleukin-15, which activate NK cells in vivo, may be a feasible method for amplifying the efficacy of immunotherapy against malignant cancers in dogs.

\section{Methods}

Cell lines and monoclonal antibodies

CMT-U334 cells (canine mammary gland tumor cells) were kindly provided by Dr. Eva Hellmen (Swedish University of Agricultural Sciences, Uppsala, Sweden). CF41.Mg (canine mammary gland tumor cells), SKBR3 (human breast carcinoma cells), DU145 (human prostate cancer cells), and K562 cells were obtained from the American Type Culture Collection (ATCC, Manassas, VA, USA). Cetuximab (Erbitux ${ }^{\circ}$ ), a chimeric IgG1 antiErbB-1 (EGFR) monoclonal antibody, was obtained from Merck KGaA (Darmstadt, Germany), and trastuzumab (Herceptin ${ }^{\circ}$ ), a humanized IgG1 monoclonal anti-ErbB-2 (HER-2) antibody, was from Roche (Hertfordshire, United Kingdom). The concentrations of cetuximab and trastuzumab used for all analyzes in this study were $10 \mu \mathrm{g} / \mathrm{ml}$ as determined by the binding assay (Additional file 1: Figure S4 and Methods). 


\section{Animals and blood collection}

Peripheral blood was obtained from nine healthy beagle dogs that were kept at the animal center of Kongju National University for research or educational purposes. All dogs had previously received routine vaccinations and had been dewormed regularly. Blood samples were collected from the jugular vein of each dog into $10 \mathrm{ml}$ of sodium-heparin tubes (Becton Dickinson, Franklin Lakes, NJ, USA). The use of animals for this study was approved by the Institutional Animal Care and Use Committee of Kongju National University (KNU_201703). All dogs used in the study were adopted by students after the research was completed.

\section{Expansion of canine NK cells}

Peripheral blood mononuclear cells (PBMCs) were isolated by discontinuous density gradient centrifugation, and canine NK cells were selectively expanded with a methods detailed in previous reports [13, 21]. In brief, isolated PBMCs $\left(3.5 \times 10^{6}\right)$ were incubated with $125 \mathrm{~Gy}$ irradiated $\mathrm{K} 562$ cells $\left(0.5 \times 10^{6}\right)$ in complete RPMI-1640 medium (WELGENE, Seoul, Korea) supplemented with 10\% FBS (WELGENE), 100 units/ml of penicillin, $100 \mu \mathrm{g} / \mathrm{ml}$ of streptomycin (WELGENE), $100 \mathrm{IU} / \mathrm{ml}$ of human interleukin (IL)-2 (PeproTec, Rocky Hill, NJ, USA), and $10 \mathrm{IU} / \mathrm{ml}$ of recombinant canine IL (rcIL)-15 (in house). Cells were stimulated with $5 \mathrm{ng} / \mathrm{ml}$ of rcIL-21 (R\&D Systems, Minneapolis, MN, USA) for the first 7 days of culture. Fresh medium with rhIL-2 and rcIL-15 was provided every other day $[13,21]$. To evaluate the capacity of IL-21 to enhance the ADCC activity of expanded NK cells, the cultured NK cells were additionally stimulated with rcIL-21 (R\&D Systems) for 2 days before harvest on days $12 \sim 15$, and the production of IFN- $\gamma$ and the cytotoxicity against trastuzumab-coated SKBR3 cells were evaluated. The purity of the cultured NK cells was examined by flow cytometry as previously described [13, 21]. Cells were stained with FITC-conjugated anti-dog CD3 (clone CA17.2A12), APC-conjugated anti-dog CD5 (clone YKIX322.3), RPE-conjugated anti-dog CD21 (clone CA2.1D6) (all from Bio-Rad, Hercules, CA, USA), unconjugated TCR $\alpha \beta$ (clone CA15.8G7), and TCR $\gamma \delta$ (clone CA20.8H1) (both from Peter Moor, UC Davis, CA, USA). For TCR $\alpha \beta$ and $T C R \gamma \delta$, Pacific Blue-conjugated goat anti-mouse IgG secondary antibody (Invitrogen, Carlsbad, CA, USA) was added.

\section{Analysis of EGFR/HER-2 expression in tumor cells}

Expression of EGFR and HER-2 protein on tumor cells was assessed by flow cytometry. The tumor cells $(2 \times$ $10^{5}$ ) were incubated with $10 \mu \mathrm{g} / \mathrm{ml}$ of cetuximab (Merck KGaA) or trastuzumab (Roche) for $15 \mathrm{~min}$ on ice. The cells were then washed three times with flow cytometry (FACS) buffer (phosphate-buffered saline, 5\% bovine serum albumin) and incubated with $2 \mu$ of Alexa Fluor 488-conjugated goat anti-human IgG antibody (Southern Biotech, Birmingham, AL, USA) for $15 \mathrm{~min}$ on ice. After washing twice with FACS buffer, FACS analysis was performed using the FACSCalibur flow cytometer (Becton Dickinson). Data were analyzed with FlowJo software (Version 10.4.1.; FlowJo, LLC, Ashland, OR, USA).

\section{Cell viability assay}

An EZ-Cytox Cell Viability Assay kit (ItsBio, Seoul, Korea) was used to determine the cytotoxic effects of cetuximab and trastuzumab against CMT-U334, SKBR3, DU145, and CF41.Mg cells for $96 \mathrm{~h}$. Cells $\left(4 \times 10^{4} /\right.$ well $)$ were cultured in a 96-well flat-bottom plate in triplicate overnight under standard culture conditions. After washing the cells twice with RPMI-1640 or DMEM medium supplemented with $10 \% \mathrm{FBS}$ and antibiotics, we exposed the cells to $10 \mu \mathrm{g} / \mathrm{ml}$ of cetuximab or $10 \mu \mathrm{g} / \mathrm{ml}$ of trastuzumab for $24,48,72$, and $96 \mathrm{~h}$, followed by washing twice with medium. The control groups were treated with medium alone or $10 \mu \mathrm{g} /$ $\mathrm{ml}$ of purified human IgG isotype control antibody (Novus Biologicals, Littleton, CO, USA). After adding $10 \mu \mathrm{l}$ of WST-1 (ItsBio) to $150 \mu \mathrm{l}$ of medium per well, the plates were incubated at $37^{\circ} \mathrm{C}$ for $30 \mathrm{~min}$ and were placed on ice for $5 \mathrm{~min}$ to stop the reaction. The absorption at $450 \mathrm{~nm}$ was measured using the Infinite M200 PRO (Salzburg Umgebung, Salzburg, Austria) device to determine the amount of formazan produced by live cells.

\section{Cell proliferation and apoptosis assay}

The effects of cetuximab and trastuzumab on the proliferation and apoptosis of tumor cells were determined by flow cytometry. CMT-U334 $\left(2 \times 10^{5}\right)$, SKBR3 $\left(4 \times 10^{5}\right)$, DU145 $\left(4 \times 10^{5}\right)$, and CF41.Mg $\left(4 \times 10^{5}\right)$ cells were seeded in 100-mm culture dishes and cultured in triplicate overnight under standard culture conditions. After washing the cells twice with medium, we incubated the cells in complete medium containing $10 \mu \mathrm{g} / \mathrm{ml}$ of cetuximab or $10 \mu \mathrm{g} / \mathrm{ml}$ of trastuzumab for $96 \mathrm{~h}$. The control groups were treated with medium alone or $10 \mu \mathrm{g} / \mathrm{ml}$ of human IgG isotype control antibody (Novus Biologicals). After harvesting the cells and following cell permeabilization using a Foxp3/Transcription factor staining buffer set (eBioscience, San Diego, CA, USA), we measured the protein levels of Ki-67 molecules, an indicator of cell proliferation, by intracellular staining using a PE-Cyanine7-labeled $\mathrm{mAb}$ against Ki-67 (eBioscience). Isotype controls were run in parallel. The apoptosis of cells was analyzed using the FITC annexin V/dead cell apoptosis kit (Invitrogen) according to the manufacturer's instructions. Flow cytometry analyses were performed using a FACSAria flow cytometer (Becton Dickinson). The data were analyzed using FlowJo software (Flowjo). 


\section{NK cell cytotoxicity and ADCC assay}

The EZ-Cytox Cell Viability Assay kit (ItsBio) was used to measure the 4-h cytotoxicity and ADCC activities of cultured NK cells, as previously described [21, 34]. Target tumor cells $\left(4 \times 10^{4} /\right.$ well $)$ were seeded in a 96-well flat-bottom plate in triplicate and were cultured overnight under standard culture conditions. The next day, the target tumor cells were washed and exposed to media alone, $10 \mu \mathrm{g} / \mathrm{ml}$ purified human IgG isotype antibody (Novus Biologicals), $10 \mu \mathrm{g} / \mathrm{ml}$ cetuxi$\mathrm{mab}$, or $10 \mu \mathrm{g} / \mathrm{ml}$ trastuzumab at $37^{\circ} \mathrm{C}$ for $30 \mathrm{~min}$. After washing the cells twice, we cultured the cells with expanded canine NK cells at a 4:1 effector-totarget (E:T) ratio at $37^{\circ} \mathrm{C}$ for $3 \mathrm{~h}$. After adding $10 \mu \mathrm{l}$ of WST-1 (ItsBio) to the well, the plates were incubated at $37^{\circ} \mathrm{C}$ for $1 \mathrm{~h}$ and placed on ice for $5 \mathrm{~min}$ to stop the reaction. The absorbance at $450 \mathrm{~nm}$ was measured using the Infinite M200 PRO (Salzburg Umgebung). The percent of cytotoxicity was calculated using the following equation: $100 \%-100 \times\left[A_{450}\right.$ of effector cell-treated target cells $-A_{450}$ of effector cells (background of effector cells)] / [ $A_{450}$ of target cells $A_{450}$ of target cells with no WST-1 (background of target cells)].

\section{Enzyme-linked immunosorbent assay (ELISA)}

IFN- $\gamma$ production in expanded NK cells in response to SKBR3 coated with trastuzumab was analyzed by ELISA as described previously [13, 21]. Target cells $\left(2 \times 10^{4}\right)$ were seeded in a 96-well microplate in triplicate and cultured at $37^{\circ} \mathrm{C}$ overnight. The next day, the cells were exposed to $10 \mu \mathrm{g} / \mathrm{ml}$ of human IgG isotype antibody or $10 \mu \mathrm{g} / \mathrm{ml}$ of trastuzumab at $37^{\circ} \mathrm{C}$ for $30 \mathrm{~min}$. The plate was then washed with medium, and expanded NK cells $\left(2 \times 10^{5}\right)$ cells were co-cultured with target cells at a 10:1 E:T ratio without cytokines. After $24 \mathrm{~h}$ of co-culture, the cell-free culture supernatants were harvested and analyzed for IFN- $\gamma$ production using DuoSet canine IFN- $\gamma$ kits (R\&D Systems, Minneapolis, MN, USA) according to the manufacturer's instructions. The cell-free supernatant from SKBR3 and NK cells cultured alone for $24 \mathrm{~h}$ was used as the control.

\section{Statistical analysis}

All statistical analyses were carried out using SPSS (Version 24.0; IBM Corp, Armonk, NY, USA). The significance of the differences between the groups was determined using the non-parametric Kruskal-Wallis test followed by post hoc comparison using the Dunn test. The Mann-Whitney $U$ test was used for comparisons across two groups. A $p$ value $<0.05$ was deemed to indicate statistical significance.

\section{Additional file}

Additional file 1: Figure S1. Expression levels of EGFR and HER-2 on the surface of canine tumor cells. Figure S2. Expression of NKp46 on cultured non-B, non-T (CD3 $\left.{ }^{-} \mathrm{CD}^{-} \mathrm{CD}^{-} 1^{-}\right)$NK lymphocytes. Figure S3. The ADCC ability of expanded canine NK cells against trastuzumab- or cetuximab-coated canine thyroid adenocarcinoma (CTAC) cells that do not express HER-2 and EGFR. Figure S4. Binding of trastuzumab and cetuximab to SKBR3 cells by flow cytometry. Methods. Cell lines and monoclonal antibody, and binding assay for trastuzumab and cetuximab. (DOCX 690 kb)

\section{Abbreviations}

ADCC: Antibody-dependent cellular cytotoxicity; CTAC: Canine thyroid adenocarcinoma; EGFR: Epidermal growth factor receptor; ELISA: Enzymelinked immunosorbent assay; FACS: Flow cytometry; HER-2: Human epidermal growth factor receptor 2; NK cells: Natural killer cells; PBMCs: Peripheral blood mononuclear cells; PI: Propidium iodide; rclL: Recombinant canine interleukin

\section{Acknowledgements}

The authors would like to thank Dr. Hellmen (Swedish University of Agricultural Sciences, Uppsala, Sweden) for providing CMT-U334 cells.

\section{Authors' contributions}

YK, SL, CK, and SA performed the experiments. SK and DS designed the experiments. DS, JL and DY interpreted the data. SK drafted the manuscript. All authors approved of the final manuscript for publication.

\section{Funding}

This research was supported by the Basic Science Research Program through the National Research Foundation of Korea (NRF) funded by the Ministry of Education (NRF-2016R1A6A11933076) and the Ministry of Science and ICT (NRF-2016R1 A2B4007817), and by the Bio-industry Technology Development Program (112016-3), Ministry of Agriculture, Food and Rural Affairs, Republic of Korea. The funders had no role in study design, data collection, analysis and interpretation, decision to publish, or preparation of the manuscript.

\section{Availability of data and materials}

The datasets used and/or analyzed during the current study available from the corresponding author on reasonable request.

Ethics approval and consent to participate

The use of animals for this study was approved by the Institutional Animal Care and Use Committee of Kongju National University (KNU_2017-03).

\section{Consent for publication}

Not applicable.

\section{Competing interests}

The authors declare that they have no competing interests.

\section{Author details}

'Department of Companion and Laboratory Animal Science, College of Industrial Science, Kongju National University, Yesan-gun, Chungnam 32439, Republic of Korea. ${ }^{2}$ Present Address: Research Institute, Vaxcell-Bio Therapeutics, Hwasun, Jellanamdo, Republic of Korea. ${ }^{3}$ Department of Integrated Life Science and Technology, Kongju National University, Yesan-gun, Chungnam, Republic of Korea. ${ }^{4}$ Present Address: CHABiolab Co.,Ltd, Seongnam-siGyeonggi-doRepublic of Korea. ${ }^{5}$ Department of Hemotology-Oncology, Chonnam National University Hwasun Hospital, Hwasun, Jeollanamdo, Republic of Korea. ${ }^{6}$ Institute of Animal Medicine, College of Veterinary Medicine, Gyeongsang National University, Jinju, Republic of Korea. ${ }^{7}$ Research Institute for Natural Products, Kongju National University, Yesan-gun, Chungnam 32439, Republic of Korea. 
Received: 4 January 2019 Accepted: 29 August 2019

Published online: 14 October 2019

\section{References}

1. Paoloni M, Khanna C. Translation of new cancer treatments from pet dogs to humans. Nat Rev Cancer. 2008;8(2):147-56.

2. Farkona S, Diamandis EP, Blasutig IM. Cancer immunotherapy: the beginning of the end of cancer? BMC Med. 2016;14:73.

3. Scott AM, Allison JP, Wolchok JD. Monoclonal antibodies in cancer therapy. Cancer Immun. 2012;12:14.

4. Alderson $\mathrm{KL}$, Sondel PM. Clinical cancer therapy by NK cells via antibody-dependent cell-mediated cytotoxicity. J Biomed Biotechnol. 2011;2011:379123.

5. Wang W, Erbe AK, Hank JA, Morris ZS, Sondel PM. NK cell-mediated antibody-dependent cellular cytotoxicity in Cancer immunotherapy. Front Immunol. 2015;6:368.

6. Kurai J, Chikumi H, Hashimoto K, Yamaguchi K, Yamasaki A, Sako T, Touge H, Makino H, Takata M, Miyata M, et al. Antibody-dependent cellular cytotoxicity mediated by cetuximab against lung cancer cell lines. Clin Cancer Res. 2007;13(5):1552-61.

7. Collins DM, O'Donovan N, McGowan PM, O'Sullivan F, Duffy MJ, Crown J. Trastuzumab induces antibody-dependent cell-mediated cytotoxicity (ADCC) in HER-2-non-amplified breast cancer cell lines. Ann Oncol. 2012; 23(7):1788-95.

8. Carson WE, Parihar R, Lindemann MJ, Personeni N, Dierksheide J, Meropol NJ, Baselga J, Caligiuri MA. Interleukin-2 enhances the natural killer cell response to Herceptin-coated Her2/neu-positive breast cancer cells. Eur J Immunol. 2001;31(10):3016-25.

9. Liang S, Niu L, Xu K, Wang X, Liang Y, Zhang M, Chen J, Lin M. Tumor cryoablation in combination with natural killer cells therapy and Herceptin in patients with HER2-overexpressing recurrent breast cancer. Mol Immunol. 2017;92:45-53

10. Cho D, Kim SK, Carson WE 3rd. NK cell-based immunotherapy for treating cancer: will it be promising? Korean J Hematol. 2011;46(1):3-5.

11. Fazekas J, Furdos I, Singer J, Jensen-Jarolim E. Why man's best friend, the dog, could also benefit from an anti-HER-2 vaccine. Oncol Lett. 2016;12(4):2271-6.

12. Anderson KL, Modiano JF. Progress in adaptive immunotherapy for Cancer in companion animals: success on the path to a cure. Vet Sci. 2015;2(4):363-87.

13. Lee SH, Shin DJ, Kim Y, Kim CJ, Lee JJ, Yoon MS, Uong TNT, Yu D, Jung JY, Cho D, et al. Comparison of phenotypic and functional characteristics between canine non-B, non-T natural killer lymphocytes and CD3(+)CD5(dim)CD21(-) cytotoxic large granular lymphocytes. Front Immunol. 2018;9:841.

14. Park JS, Withers SS, Modiano JF, Kent MS, Chen M, Luna Jl, Culp WTN, Sparger EE, Rebhun RB, Monjazeb AM, et al. Canine cancer immunotherapy studies: linking mouse and human. J Immunother Cancer. 2016;4:97

15. Singer J, Fazekas J, Wang W, Weichselbaumer M, Matz M, Mader A, Steinfellner W, Meitz S, Mechtcheriakova D, Sobanov Y, et al. Generation of a canine anti-EGFR (ErbB-1) antibody for passive immunotherapy in dog cancer patients. Mol Cancer Ther. 2014;13(7):1777-90.

16. Ito D, Brewer S, Modiano JF, Beall MJ. Development of a novel anti-canine CD20 monoclonal antibody with diagnostic and therapeutic potential. Leuk Lymphoma. 2015;56(1):219-25.

17. Rue SM, Eckelman BP, Efe JA, Bloink K, Deveraux QL, Lowery D, Nasoff M. Identification of a candidate therapeutic antibody for treatment of canine Bcell lymphoma. Vet Immunol Immunopathol. 2015;164(3-4):148-59.

18. Singer J, Weichselbaumer M, Stockner $T$, Mechtcheriakova $D$, Sobanov $Y$, Bajna E, Wrba F, Horvat R, Thalhammer JG, Willmann M, et al. Comparative oncology: ErbB-1 and ErbB-2 homologues in canine cancer are susceptible to cetuximab and trastuzumab targeting. Mol Immunol. 2012;50(4):200-9.

19. Dhupkar $P$, Dowling $M$, Cengel $K$, Chen B. Effects of anti-EGFR antibody cetuximab on androgen-independent prostate cancer cells. Anticancer Res. 2010;30(6):1905-10.

20. Park YK, Shin DJ, Cho D, Kim SK, Lee JJ, Shin MG, Ryang DW, Lee JS, Park $\mathrm{MH}$, Yoon $\mathrm{JH}$, et al. Interleukin-21 increases direct cytotoxicity and IFNgamma production of ex vivo expanded NK cells towards breast cancer cells. Anticancer Res. 2012;32(3):839-46.

21. Shin DJ, Lee SH, Park JY, Kim JS, Lee JJ, Suh GH, Lee YK, Cho D, Kim SK. Interleukin-21 induces proliferation and modulates receptor expression and effector function in canine natural killer cells. Vet Immunol Immunopathol. 2015;165(1-2):22-33.

22. Shin DJ, Park JY, Jang YY, Lee JJ, Lee YK, Shin MG, Jung JY, Carson WE 3rd, Cho D, Kim SK. Ex vivo expansion of canine cytotoxic large granular lymphocytes exhibiting characteristics of natural killer cells. Vet Immunol Immunopathol. 2013;153(3-4):249-59.

23. Yarden Y, Sliwkowski MX. Untangling the ErbB signalling network. Nat Rev Mol Cell Biol. 2001;2(2):127-37.

24. Ressel L, Puleio R, Loria GR, Vannozzi I, Millanta F, Caracappa S, Poli A. HER-2 expression in canine morphologically normal, hyperplastic and neoplastic mammary tissues and its correlation with the clinical outcome. Res Vet Sci. 2013;94(2):299-305.

25. Muhammadnejad A, Keyhani E, Mortazavi P, Behjati F, Haghdoost IS. Overexpression of her-2/neu in malignant mammary tumors; translation of clinicopathological features from dog to human. Asian Pac J Cancer Prev. 2012;13(12):6415-21.

26. Flint AF, U'Ren L, Legare ME, Withrow SJ, Dernell W, Hanneman WH. Overexpression of the erbB-2 proto-oncogene in canine osteosarcoma cell lines and tumors. Vet Pathol. 2004;41(3):291-6.

27. Terragni R, Casadei Gardini A, Sabattini S, Bettini G, Amadori D, Talamonti C, Vignoli M, Capelli L, Saunders JH, Ricci M, et al. EGFR, HER-2 and KRAS in canine gastric epithelial tumors: a potential human model? PLoS One. 2014; 9(1):e85388

28. Fraser AR, Bacci B, le Chevoir MA, Long SN. Epidermal growth factor receptor and Ki-67 expression in canine gliomas. Vet Pathol. 2016;53(6):1131-7.

29. Pegram MD, Konecny GE, O'Callaghan C, Beryt M, Pietras R, Slamon DJ. Rational combinations of trastuzumab with chemotherapeutic drugs used in the treatment of breast cancer. J Natl Cancer Inst. 2004;96(10):739-49.

30. Mayfield S, Vaughn JP, Kute TE. DNA strand breaks and cell cycle perturbation in herceptin treated breast cancer cell lines. Breast Cancer Res Treat. 2001;70(2):123-9.

31. Foltz JA, Somanchi SS, Yang Y, Aquino-Lopez A, Bishop EE, Lee DA. NCR1 expression identifies canine natural killer cell subsets with phenotypic similarity to human natural killer cells. Front Immunol. 2016;7:521.

32. Grondahl-Rosado C, Bonsdorff TB, Brun-Hansen HC, Storset AK. NCR1+ cells in dogs show phenotypic characteristics of natural killer cells. Vet Res Commun. 2015:39(1):19-30.

33. Lee SH, Shin DJ, Kim SK. Generation of recombinant canine interleukin-15 and evaluation of its effects on the proliferation and function of canine NK cells. Vet Immunol Immunopathol. 2015;165(1-2):1-13.

34. Park JY, Shin DJ, Lee SH, Lee JJ, Suh GH, Cho D, Kim SK. The anti-canine distemper virus activities of ex vivo-expanded canine natural killer cells. Vet Microbiol. 2015;176(3-4):239-49.

35. Bergeron LM, McCandless EE, Dunham S, Dunkle B, Zhu Y, Shelly J, Lightle S, Gonzales A, Bainbridge G. Comparative functional characterization of canine IgG subclasses. Vet Immunol Immunopathol. 2014;157(1-2):31-41.

36. Cooley S, Burns LJ, Repka T, Miller JS. Natural killer cell cytotoxicity of breast cancer targets is enhanced by two distinct mechanisms of antibodydependent cellular cytotoxicity against LFA-3 and HER2/neu. Exp Hematol. 1999;27(10):1533-41.

\section{Publisher's Note}

Springer Nature remains neutral with regard to jurisdictional claims in published maps and institutional affiliations.

Ready to submit your research? Choose BMC and benefit from:

- fast, convenient online submission

- thorough peer review by experienced researchers in your field

- rapid publication on acceptance

- support for research data, including large and complex data types

- gold Open Access which fosters wider collaboration and increased citations

- maximum visibility for your research: over $100 \mathrm{M}$ website views per year

At $\mathrm{BMC}$, research is always in progress.

Learn more biomedcentral.com/submission 